\title{
Recombinant PTH for Chronic Primary Hypoparathyroidism
}

\author{
Elizabeth Zolper ${ }^{1}$, Ira Berger ${ }^{2}$ and Gerti Tashko*3 \\ ${ }^{1}$ Student, Georgetown University School of Medicine, USA \\ ${ }^{2}$ Pulmonologist, Clinical Instructor, Georgetown University School of Medicine, USA \\ ${ }^{3}$ Endocrinologist, Diabetologist, Hypertension Specialist, USA
}

Submission: September 26, 2017; Published: October 13, 2017

*Corresponding author: Gerti Tashko, Endocrinologist, Diabetologist, Hypertension Specialist, USA, Email: gtash001@gmail.com

\begin{abstract}
Primary hypoparathyroidism (PHPT) is a rare endocrine condition defined by hypocalcemia and deficient parathyroid hormone (PTH). It is primarily managed with high dose oral calcium and vitamin D supplementation instead of targeting the root cause of deficient PTH. Conventional treatment is difficult to manage and often inadequate at controlling symptoms and preventing complications. RhPTH (1-84) is a recombinant form of PTH that acts as a direct substitute to the native hormone. It is a novel therapy that allows significant dose reductions in calcium and vitamin D supplementation, while achieving improved serum calcium, phosphate and calcium-phosphate product levels. These biochemical advantages over the conventional therapy can translate to significant clinical benefits: reduced adverse events and improved quality of life. Our patient experienced just that with PTH replacement therapy. We propose a simple and practical protocol of how to initiate and titrate PHPT treatment. We emphasize the need for RhPTH(1-84) in all patients with resistant or refractory hypoparathyroidism.
\end{abstract}

keywords: Hypocalcemia; Hypoparathyroidism; Hyperphosphatemia; Hypercalciuria; Activated vitamin D

Abbreviations: PHPT: Primary Hypoparathyroidism; PTH: Parathyroid Hormone; RhPTH(1-84): Recombinant Human Parathyroid Hormone (1-84); FDA: Food and Drug Administration; D3: Vitamin D3; Calcitriol: Vitamin D 1,25-dihydroxy

\section{Introduction}

Primary hypoparathyroidism is an endocrine disorder defined by hypocalcemia and deficient or dysfunctional parathyroid hormone. The physiological role of parathyroid hormone is to maintain bone remodeling, activate vitamin D 25-hydroxy to D 1,25-dihydroxy, and increase urinary calcium reabsorption and phosphate excretion. Consequently hyperphosphatemia, hypercalciuria, and decreased levels of active vitamin D are commonly seen in PHPT [1]. The main cause of hypoparathyroidism is iatrogenic. Up to $75 \%$ of cases are due to surgery of the anterior neck $[2,3]$. Far less common etiologies include autoimmune disorders, infiltrative disease, heavy metal overload, and radiation exposure [3].

Hypoparathyroidism is estimated to affect 77,000 patients in the United States [2]. Although of low prevalence, it can have serious complications; thus, timely and appropriate treatment is essential. Depending on etiology, the disorder can carry an increased risk of ischemic heart disease, chronic kidney disease, and depression [3]. The rarity of hypoparathyroidism means that few physicians have firsthand experience managing the disease. Primary hypoparathyroidism also leads to individual suffering. A study by Hadker et al. found that $45 \%$ of patients with hypoparathyroidism had a significant reduction in overall quality of life [4]. About $72 \%$ of these patients experienced greater than ten associated symptoms, including fatigue, paresthesia, and tetany even when they were managed with conventional therapy [4]. The burden from the reported complaints has a large effect on emotional and mental wellbeing; as the majority of patients also reported symptoms of depression or anxiety over a 12 month period [4].

\section{Conventional Therapy}

Conventional therapy for primary hypoparathyroidism consists of high dose oral calcium and vitamin D supplementation [5]. Vitamin D can be provided in the form of pre-hormone D2 or D3, or activated D1, 25-dihydroxy. The intake of calcium and vitamin D is titrated based on six therapeutic goals: hypocalcemia symptom relief, low-normal fasting serum calcium, highnormal fasting serum phosphate, hypercalciuria prevention, calcium-phosphate product levels below $55 \mathrm{mg} 2 / \mathrm{dL} 2$, and prevention of ectopic calcification in kidneys and soft tissue [5]. Requirements for calcium and vitamin D supplementation 
are highly variable, thus placing patients at risk for acute and potentially life threatening extremes of hypocalcemia and hypercalcemia [1]. As a result, patients may require frequent blood work to monitor calcium levels, multiple appointments with their managing physician, increased use of emergency department, and more days spent in the hospital than the general public [4]. Conventional therapy may also contribute to ectopic calcifications in sites like the vasculature, brain, and kidneys [5,6]. Chronic hyperphosphatemia is responsible for ectopic calcifications via increased calcium-phosphate product, which can lead to permanent organ damage [6].

\section{Novel Therapy}

The new recombinant PTH therapy, rhPTH(1-84) (marketed under brand name Natpara) acts as a replacement to the native parathyroid hormone and its biochemical activities - unlike conventional treatment, which lacks the ability to promote urinary phosphate excretion, renal calcium reabsorption, bone turnover, and activation of vitamin D 25-hydroxy [7]. Clinical trials have shown that rhPTH(1-84), FDA approved in January 2015 , is associated with significantly lower serum phosphate and calcium-phosphate product levels after 24 weeks compared to placebo [7]. It maintains appropriate serum calcium measures while allowing dose reductions in calcium and vitamin D intake [7]. The REPLACE phase III clinical trial, pivotal to FDA approval of the drug, found that $43 \%$ of patients receiving rhPTH(1-84) were able to cease vitamin $\mathrm{D}$ supplementation and maintain a calcium dose of less than $500 \mathrm{mg}$ per day [8]. See Figure 1 for changes in average oral calcium and calcitriol doses over the 24 week study period. Further evidence is needed to assess the impact of rhPTH(1-84) therapy on quality of life. Meaningful reductions in ectopic calcifications have yet to be demonstrated [8].
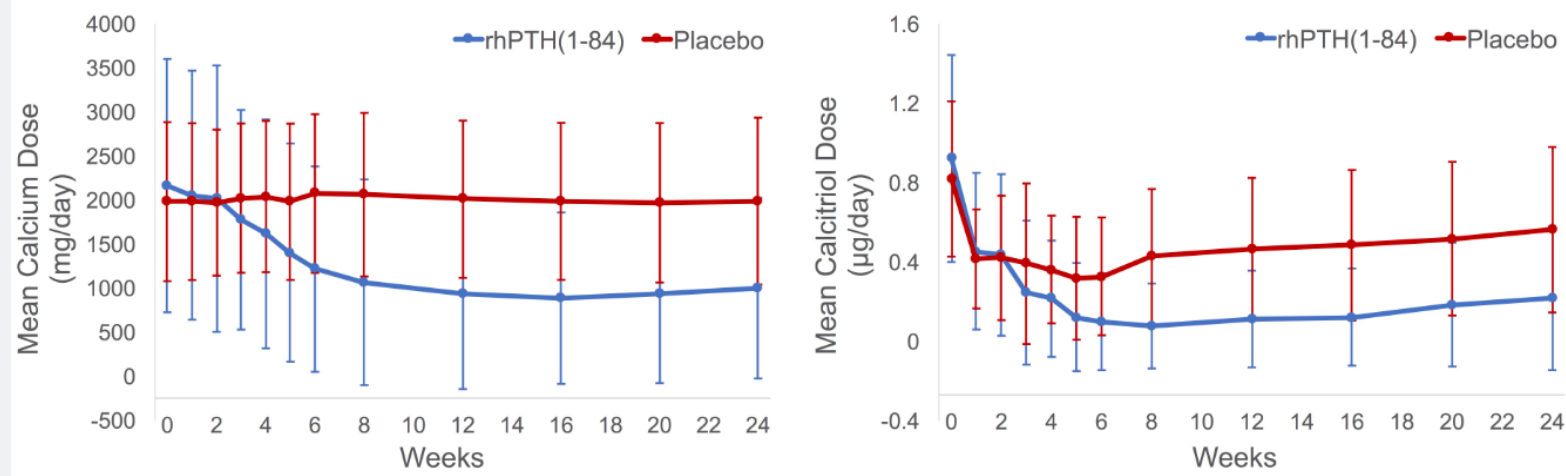

Figure 1: Changes in mean oral calcium and calcitriol doses throughout the REPLACE study in patients receiving rhPTH(1-84) vs. placebo [8]. Graphs are constructed from original study data.

Despite evidence for increased therapeutic effect of rhPTH(1-84) compared to conventional treatment, clinical indications for rhPTH(1-84) are limited to patients with primary hypoparathyroidism who do not respond to the conventional approach [9]. This is due to the hypothetical increased risk of osteosarcoma, as some rats developed the malignancy during animal testing [10]. The FDA also reports an increased incidence of side effects, such as headaches, nausea, and paresthesia with rhPTH(1-84) compared to placebo [9].

\section{Patient Case}

A 40-year-old woman with a nine year history of idiopathic hypocalcemia, chronic fatigue, exercise intolerance, tachycardia, polyarthralgia, and menorrhagia presented to our clinic for evaluation. Previous therapy for refractory hypocalcemia included calcium 600mg/D3 200 IU PO daily and calcitriol $0.25 \mu \mathrm{g}$ PO twice a day. She had consulted with at least seven endocrinologists, yet symptoms and serum calcium had not improved. The etiology of hypocalcemia remained unclear, which resulted in frequent emergency room visits.

At initial presentation in September 2016, the patient was found to be hypocalcemic at $7.9 \mathrm{mg} / \mathrm{dL}$ and vitamin D 25-hydroxy insufficient at $24 \mathrm{ng} / \mathrm{mL}$ in the setting of non-elevated intact PTH of $37 \mathrm{pg} / \mathrm{mL}$ (15-65 pg/mL). Clinical suspicion was high for primary hypoparathyroidism of idiopathic or autoimmune etiology in the absence of chronic hypomagnesemia, neck surgery, radiation exposure, or systemic infiltrative illness. Therapeutic regimen was first optimized by increasing calcium $600 \mathrm{mg} / \mathrm{D} 3200 \mathrm{IU}$ to two tablets twice daily, maintaining calcitriol $0.25 \mu \mathrm{g}$ PO twice daily, and adding vitamin D3 $5000 \mathrm{IU}$ PO daily. This high dose regimen failed to alleviate hypocalcemia and its clinical sequelae. Given continued debilitating symptoms, PTH replacement therapy was then considered in advance of doubling the dose of calcitriol. After an extensive preauthorization process, rhPTH(1-84) 50 mcg subcutaneous daily 
injection was approved and initiated in early 2017. Astonishingly, she experienced a radical improvement within four months.

Table 1: Case Summary.

\begin{tabular}{|c|c|c|c|c|c|}
\hline \multicolumn{3}{|c|}{ Before intervention September 2016} & \multicolumn{3}{|c|}{ After intervention July 2017} \\
\hline Key Labs & Key Symptoms & Medications & Key Labs & Key Symptoms & Medications \\
\hline Ca: 7.9 mg/dL & Chronic Fatigue & $\begin{array}{l}\text { Calcium 600mg / } \\
\text { D3 } 200 \text { IU PO daily } \\
\text { Later, the dose was } \\
\text { quadrupled }\end{array}$ & Ca: $8.3,8.0 \mathrm{mg} / \mathrm{dL}$ & $\begin{array}{l}\text { Able to travel } \\
\text { internationally }\end{array}$ & $\begin{array}{l}\text { rhPTH(1-84) } 50 \text { mcg } \\
\text { SubQ daily }\end{array}$ \\
\hline Alb: $3.8 \mathrm{~g} / \mathrm{dL}$ & Exercise Intolerance & $\begin{array}{l}\text { Activated vitamin D: } \\
0.25 \mu \mathrm{g} \text { PO BID }\end{array}$ & Alb: $3.9 \mathrm{~g} / \mathrm{dL}$ & $\begin{array}{l}\text { Able to return to } \\
\text { running }\end{array}$ & \multirow{6}{*}{$\begin{array}{c}\text { No oral } \\
\text { supplementation }\end{array}$} \\
\hline iPTH: 37 pg/mL & Tachycardia & \multirow{5}{*}{$\begin{array}{l}\text { Later, Vitamin D3 } \\
5,000 \text { IU daily was } \\
\text { added }\end{array}$} & iPTH: 44 pg/mL & Resolved & \\
\hline $\begin{array}{l}\text { Vitamin D 25-OH: } 24 \\
\mathrm{ng} / \mathrm{mL}\end{array}$ & Polyarthralgia & & $\begin{array}{l}\text { Vitamin D 25-OH: } \\
29.3 \mathrm{ng} / \mathrm{mL}\end{array}$ & Resolved & \\
\hline $\begin{array}{l}\text { Vitamin D 1,25-diOH: } \\
32 \mathrm{pg} / \mathrm{mL}\end{array}$ & Menorrhagia & & $\begin{array}{l}\text { Vitamin D 1,25-diOH: } \\
41 \mathrm{pg} / \mathrm{mL}\end{array}$ & $\begin{array}{c}\text { Menorrhagia of } \\
\text { decreased frequency }\end{array}$ & \\
\hline \multirow[b]{2}{*}{ eGFR: $102 \mathrm{~mL} / \mathrm{min}$} & Frequent clinic visits & & \multirow[b]{2}{*}{ eGFR: $107 \mathrm{~mL} / \mathrm{min}$} & $\begin{array}{l}\text { Routine follow up and } \\
\text { labs every } 3 \text { months }\end{array}$ & \\
\hline & $\begin{array}{c}\text { Frequent ER } \\
\text { visits and hospital } \\
\text { admissions }\end{array}$ & & & $\begin{array}{c}\text { No new ER or hospital } \\
\text { admissions }\end{array}$ & \\
\hline
\end{tabular}

Within 120 days of the new therapy initiation, the patient's serum calcium rose from $7.9 \mathrm{mg} / \mathrm{dL}$ to $8.3 \mathrm{mg} / \mathrm{dL}$. She was asymptomatic for the first time in ten years and stated that the new medication "saved her life". She was able to resume her normal routine and began exercising again. After sixteen years she was finally able to travel internationally to her home country. Although calcium $600 \mathrm{mg} / \mathrm{D} 3200 \mathrm{IU}$, calcitriol $0.25 \mu \mathrm{g}$, and vitamin D3 5,000 IU were later discontinued, her serum calcium remained reasonable at $8.0 \mathrm{mg} / \mathrm{dL}$. As of July 2017, she continued to have full resolution of her symptoms except for menorrhagia. The only adverse effect reported by the patient was a nine pound weight gain over a six month period. We speculate that weight gain was due to improved underlying illness and not a side effect of $\operatorname{rhPTH}(1-84)$. See Table 1 for changes in laboratory values, symptoms and use of medications during the course of the treatment.

\section{Discussion}

Evidence from randomized clinical trials is limited in regard to enhanced quality of life with recombinant PTH. However, the dramatic biochemical and clinical recovery of our patient with refractory primary hypoparathyroidism supports a more proactive approach to rhPTH(1-84) initiation. Although there is a theoretical elevated risk of osteosarcoma, findings from REPLACE trial established that rhPTH(1-84) did not increase the rates of adverse events when compared to placebo [8]. Disadvantages of rhPTH(1-84) include high cost, $\$ 5,287$ for a 14 dose cartridge giving an estimated yearly cost of $\$ 137,000$, [11] and the inconvenience of daily subcutaneous injections. The gravity of these drawbacks is highly variable among individuals. Our patient reports that the once daily subcutaneous administration was more convenient and easier to adhere to than her original regimen which required her to take several pills multiple times a day.

Low awareness is another barrier to $\operatorname{rhPTH}(1-84)$ therapy. It is primarily due to the recent FDA approval of the drug in the context of a rare illness. Our patient reported that her own physicians were also unfamiliar with the recombinant PTH therapy. Therefore, patient and provider awareness is important for proper, safe, and early intervention. Future randomized control trials are needed to elucidate the effect of rhPTH(1-84) on quality of life measured by patient-oriented outcomes such as symptom burden, frequency of laboratory testing and office visits, trips to emergency department, and occupational days lost. Positive results from these studies would further raise the familiarity of recombinant PTH therapy among physicians and particularly endocrinologists.

Based on a review of the literature and clinical experience we propose the following simple and practical intervention to chronic primary hypoparathyroidism:

a) Start and titrate calcium and vitamin D2 or D3 supplementation, [12] targeting serum calcium in the lownormal range and vitamin D 25-hydroxy levels in the 50s to 60 s. This is a reasonable approach for chronic primary hypoparathyroidism as many patients have only partial PTH deficiency.

b) If unable to achieve desired results, then initiate and titrate activated vitamin D 1, 25-dihydroxy (calcitriol) [5]. Hypercalciuria needs to be avoided as it can increase the risk of nephrolithiasis and nephrocalcinosis. If hypercalciuria is mild, adjunct thiazide diuretic can be used. Targets for serum calcium and vitamin D levels remain the same. 
c) If hypocalcemia or hypercalciuria persist, then we recommend starting PTH replacement therapy while lowering or discontinuing calcium and vitamin D supplementation.

\section{Conclusion}

Primary hypoparathyroidism is rare and difficult to manage. Conventional therapy often involves multiple daily oral doses of calcium, vitamin D2, vitamin D3 and vitamin D 1,25-dihydroxy. $\mathrm{RhPTH}(1-84)$ is a recent therapeutic advance that targets the root cause of primary hypoparathyroidism. It is a hormonal replacement therapy consistent with the gold standard approach to most endocrine deficiencies. Here we propose a simple and practical protocol of how to initiate and titrate PHPT intervention. Close patient-physician communication is necessary to identify treatment barriers and triggers for therapy escalation. We highly recommend the use of recombinant PTH in patients with resistant or refractory hypoparathyroidism. Our patient's clinical presentation and resolution supports this approach.

\section{References}

1. Cusano NE, Rubin MR, Sliney J, Bilezikian JP (2012) Mini-review: new therapeutic options in hypoparathyroidism. Endocrine 41(3): 410414.

2. Powers J, Joy K, Ruscio A, Lagast H (2013) Prevalence and incidence of hypoparathyroidism in the United States using a large claims database. J Bone Miner Res 28(12): 2570-2576.
3. Clarke BL, Brown EM, Collins MT, Juppner H, Lakatos p, et al. (2016) Epidemiology and Diagnosis of Hypoparathyroidism. J Clin Endocrinol Metab 101(6): 2284-2299.

4. Hadker N, Egan J, Sanders J, Lagast H, Clarke BL (2014) Understanding the burden of illness associated with hypoparathyroidism reported among patients in the PARADOX study. Endocr Pract 20(7): 671-679.

5. Bilezikian JP, Brandi ML, Cusano NE, Mannstadt M, Rizzoli R, et al. (2016) Management of Hypoparathyroidism: Present and Future. J Clin Endocrinol Metab 101(6): 2313-2324.

6. Shoback DM, Bilezikian JP, Costa AG, Dempsteer D, Khan AA, et al. (2016) Presentation of Hypoparathyroidism: Etiologies and Clinical Features. J Clin Endocrinol Metab 101(6): 2300-2312.

7. Clarke BL, Vokes TJ, Bilezikian JP, Shoback DM, Lagast H, et al. (2017) Effects of parathyroid hormone rhPTH(1-84) on phosphate homeostasis and vitamin D metabolism in hypoparathyroidism: REPLACE phase 3 study. Endocrine 55(1): 273-282.

8. Mannstadt M, Clarke BL, Vokes T (2013) Efficacy and safety of recombinant human parathyroid hormone (1-84) in hypoparathyroidism (REPLACE): a double-blind, placebo-controlled, randomised, phase 3 study. Lancet Diabetes Endocrinol 1(4): 275-283.

9. (2017) Drug Trials Snapshot: NATPARA (parathyroid hormone).

10. Jolette J, Wilker CE, Smith SY (2006) Defining a noncarcinogenic dose of recombinant human parathyroid hormone 1-84 in a 2-year study in Fischer 344 rats. Toxicol Pathol 34(7): 929-940.

11. Lexi-Comp, Inc. (Lexi-Drugs $®)$ (2017).

12. Streeten EA, Mohtasebi Y, Konig M, Davidoff L, Ryan K (2017) Hypoparathyroidism: Less Severe Hypocalcemia With Treatment With Vitamin D2 Compared With Calcitriol. J Clin Endocrinol Metab 102(5): 1505-1510.

Your next submission with Juniper Publishers
will reach you the below assets
- Quality Editorial service
- Swift Peer Review
- Reprints availability
- E-prints Service
- Manuscript Podcast for convenient understanding
- Global attainment for your research
- Manuscript accessibility in different formats
( Pdf, E-pub, Full Text, Audio)
- Unceasing customer service
Track the below URL for one-step submission
https://juniperpublishers.com/online-submission.php

